Schröter, K., Barendrecht, M., Bertola, M., Ciullo, A., da Costa, R. T., Cumiskey, L., Curran, A., Diederen, D., Farrag, M., Holz, F., Khanal, S., Manocsoc, M., Metin, A. D., Sairam, N., Shustikova, I., Sosa, J. (2021): Large-scale flood risk assessment and management: Prospects of a systems approach. - Water Security, 14, 100109.

https://doi.org/10.1016/j.wasec.2021.100109 
This is a preprint of the article which has been published in Water Security.

Please cite as:

Schröter, K., Barendrecht, M., Bertola, M., Ciullo, A., da Costa, R.T., Cumiskey, L., Curran, A., Diederen, D., Farrag, M., Holz, F., Khanal, S., Manocsoc, M., Metin, D., Sairam, N., Shustikova, I., Sosa, J., 2021. Large-scale flood risk assessment and management: Prospects of a systems approach. Water Security 14, 100109.

https://doi.org/10.1016/j.wasec.2021.100109 


\title{
Large-scale flood risk assessment and management: prospects of a systems approach
}

\author{
Kai Schröter ${ }^{\mathrm{a}}$, Marlies Barendrecht ${ }^{\mathrm{d}}$, Miriam Bertola ${ }^{\mathrm{d}}$, Alessio Ciullo $^{\mathrm{c}}$, \\ Ricardo Tavares da Costa $^{\mathrm{e}}$, Lydia Cumiskey ${ }^{\mathrm{j}}$, Alex Curran ${ }^{\mathrm{h}}$, Dirk Diederen ${ }^{\mathrm{f}}$, \\ Mostafa Farrag $^{\mathrm{a}}$, Friederike Holz ${ }^{\mathrm{j}}$, Sonu Khanal ${ }^{\mathrm{b}}$, Maya Manocsoc ${ }^{\mathrm{a}}$, Duha \\ Metin $^{\mathrm{a}}$, Nivedita Sairam ${ }^{\mathrm{a}}$, Iuliia Shustikova ${ }^{\mathrm{g}}$, Jeison Sosa ${ }^{\mathrm{i}}$ \\ ${ }^{a}$ German Research Centre for Geosciences GFZ, Section Hydrology, Potsdam, Germany \\ ${ }^{b}$ Future Water, Wageningen, Netherlands \\ ${ }^{c}$ Institute for Environmental Decisions, ETH Zurich, Zurich, Switzerland \\ ${ }^{d}$ Institute of Hydraulic Engineering and Water Resources Management, Vienna University \\ of Technology, Vienna, Austria \\ ${ }^{e}$ GECOSistema srl, Rimini, Italy \\ ${ }^{f}$ HR Wallingford, Wallingford, UK \\ ${ }^{g}$ DICAM, University of Bologna, School of Engineering, Bologna, Italy \\ ${ }^{h}$ Deltares, Unit for Inland Water Systems, Flood Risk Management, Delft, Netherlands \\ ${ }^{i}$ University of Bristol, School of Geographical Sciences, Bristol, UK \\ ${ }^{j}$ Flood Hazard Research Centre, Middlesex University, London, UK
}

\begin{abstract}
Fluvial flood risk systems are characterised by complex interactions and feedbacks as well as subject to changes of hazard, exposure and vulnerability. Disregarding spatial and temporal dependencies and changes in the components of risk introduces biases to risk estimates. A systems approach to large-scale flood risk assessment and management is proposed to account for the complexity and dynamic nature of flood risk. The systems approach provides methods and tools that offer a more comprehensive view to flood risk, reveal the relevant interactions, and quantify feedbacks in flood risk systems. Policymakers and flood risk managers can benefit from the systems approach in the development of comprehensive risk reduction strategies.
\end{abstract}

\section{Introduction}

Globally, floods are among the most destructive natural hazards. During recent decades floods have affected billions of people (CRED, 2015) and have caused an annual average economic damage of about USD 100 million (Ward 
5 et al., 2017). Large-scale floods affect extended areas of several thousands of square kilometres encompassing multiple catchments with national and regional direct impacts. At this scale, important interactions and feedbacks between hazard, exposure and vulnerability processes, as well as dynamic developments of the flood risk system may emerge, that need to be taken into consideration to obtain more accurate and reliable risk estimates (Vorogushyn et al., 2018).

To account for this complexity and the dynamic nature of flood risk a system approach is recommended. A systems approach starts from the notion that the whole is something besides the parts and seeks to have a deep understanding of the big picture with all its components. In this way it aims to make problems more tractable and gives new insights when the complex interplay of its components are taken into account in their overall impact. With regard to flood risk, a systems approach addresses the interactions and feedbacks between different components of risk and the temporal evolution of flood risk drivers (Tobin, 1995; Merz et al., 2015).

A fluvial flood risk system comprises a chain of meteorological, hydrological, open channel flow, inundation and damage processes (Merz et al., 2006). Flood risk arises from these processes usually triggered by rainfall which forms runoff in the affected catchments depending on climatic, topographic, land cover and soil (moisture) conditions. The catchment runoff then concentrates in creeks and propagates within the river network. Discharges above the bankfull capacity induce inundations and affect exposed elements. While the image of a chain may suggest a sequence of processes, it is important to recognize that interactions and feedbacks may interlink some of these components in a complex way (Fig. 1). Accordingly, one driver may influence different risk components diso rectly or indirectly and may be subject to changes (Klijn et al., 2015; de Bruijn et al., 2017; Vorogushyn et al., 2018).

One example of interactions is the one between the atmosphere and catchment sub-systems. Flood generation depends on the spatial and temporal patterns of precipitation and catchment wetness. The interplay of both controls 35 gives rise to spatially distributed flood magnitudes (Schröter et al., 2015; Nied 


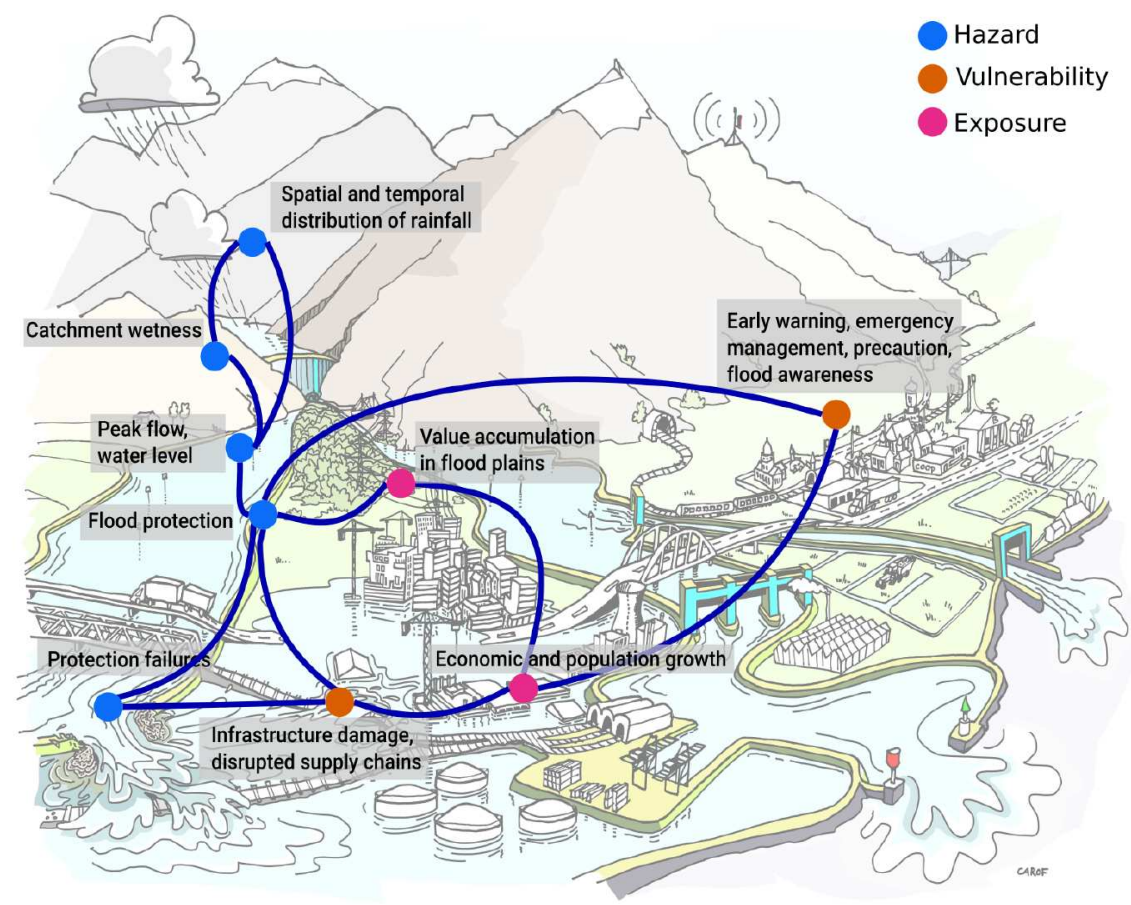

Figure 1: Stylized representation of a flood risk system with examples for interrelations between the components of risk. Background drawing $@$ Carof-Beeldleveranciers 
et al., 2013; Tarasova et al., 2019). Neglecting this variability and instead assuming homogeneous return periods of flood peaks throughout the entire catchment may result in inaccurate flood risk estimates (Falter et al., 2015; Metin et al., 2020).

40 A second example is the upstream-downstream interaction in the river-dikefloodplain sub-system. The creation of detention areas and/or the occurrence of levee breaches reduces flood levels and the probability of flooding downstream, (e.g. Pinter, 2005; Vorogushyn et al., 2012) In contrast, local flood protection schemes induce higher flow rates that propagate and may aggravate flood risk 45 downstream (e.g Remo et al., 2012; Wyżga et al., 2018). For example, in 2002 a severe flood occurred in the Elbe River in Germany, which caused losses to the federal states of Saxony (upstream) and Saxony-Anhalt (downstream) of about EUR 8.70 million and EUR 1.75 million, respectively (Thieken et al., 2016). After the flood, the state of Saxony invested in levee reinforcement and other flood protection measures. About ten years later, in June 2013, another severe flood hit the Elbe River (Schröter et al., 2015). The reinforced embankments along the Elbe River in Saxony could withstand the extreme water levels, and thus led to lower losses in Saxony (around EUR 1.19 million). However downstream, in Saxony-Anhalt, losses were higher than those experienced in 2002 (around ${ }_{55}$ EUR 1.92 million) and a debate arose on the effect of the reinforced levees upstream on flood levels downstream (Thieken et al., 2016). Ignoring these effects often leads to suboptimal risk reduction strategies. A systems approach looks into these effects and assesses the changes in risk across the whole system as a consequence of measures implemented locally, and enables to include these 60 aspects into decision making.

A third example is related to changes in exposure and vulnerability which alter the socio-economic sub-systems affected by flooding. Individuals may, for instance, undertake private precautionary measures such as flood barriers, wetproofing, or adaptive building use in order to lower the vulnerability of house65 holds and eventually reduce flood losses (e.g. Bubeck et al., 2012). The implementation of private precaution is often influenced by factors such as awareness, 
past flood experience, level of protection and other socio-economic and dwelling characteristics. For example, strengthening flood protection schemes, as in the above example for the federal state of Saxony (Germany), reduces the frequency of flooding locally. As a consequence, this may attract new settlements in the hinterland and reduce the motivation to implement precautionary measures. Hence, this "levee effect" may increase exposure and vulnerability, eventually resulting in higher losses in case of extreme floods (Tobin, 1995; Baldassarre et al., 2013).

These examples illustrate that current practice in flood risk assessment and management often takes a limited view that ignores interactions, feedbacks and changes in flood risk systems, particularly at large scales. This is both due to limited awareness of complex interactions and to a lack of methods to quantify and account for these interactions.

Taking a systems perspective helps in understanding the interplay of physical and societal processes such as hydro-meteorological extremes, flood protection schemes and risk awareness and perception in a highly diverse stakeholder landscape with multi faceted interests and goals. Implementing a systems approach requires enhanced models, tools and datasets that enable the analysis of interactions in flood risk systems, give insights into system behaviour and enhance the use of large data volumes to comprehensively assess flood risk in large regions.

This paper highlights recent advancements in terms of approaches, methods and tools to support a systems approach in large-scale flood risk assessment and management. It gives examples for 1) methods that provide spatially consistent hazard scenarios for large-scale risk assessment, 2) the use of new technologies in comprehensive risk models to accommodate the thirst for data and to reduce computing times. 3) fully coupled river-levee-floodplain models that take into account failure mechanisms of flood defenses and resulting flood and inundation processes as well as the spatial redistribution of risk such as upstreamdownstream interactions, 4) extended analytical frameworks for interactions in human-flood systems taking changes in flood risk drivers and human behaviour into account. 
These examples are based on research and outcomes achieved in the MarieSkłodowska-Curie European Training Network 'SYSTEM-RISK'. The aim of this paper is to offer an overview of these recent developments for enhancing flood risk assessment and management. Readers who are interested in the details of the approaches and methods may refer to the original research papers.

\section{New approaches, methods and tools for a systems approach in flood risk assessment and management}

\subsection{Spatially consistent and unprecedented hazard scenarios}

Flood risk assessment and management often build on local-scale hazard and risk mapping approaches. Piecing together these local results for large-scale risk assessments falls short in consistently representing the spatial variability of floods and their consequences. Yet, certain purposes, such as strategic planning or estimating worst-case scenarios at the national or continental level, require spatially coherent risk estimates. This makes it necessary to assess floods over large regions with risk drivers that change over time.

Diederen et al. (2019) have developed a new statistical methodology for the generation of spatially coherent river discharge peaks over multiple river basins that retain the observed dependence structure between peaks of flood events at 298 different locations in Europe. The approach builds on noise removal and wave tracking methods for the identification of flood waves across major European river basins (for an animated illustration of discharge waves in major European rivers for pan-European flood risk assessment cf. URL: https://av.tib.eu/media/40894). A mixture multi-variate dependence model is used to capture the dependence structure of discharge peaks between all locations (within and across catchments) and to create a catalogue of spatially coherent synthetic flood event set. Similarly, the stochastic weather generator proposed by Diederen and Liu (2019) is a new approach to simulate highresolution precipitation events for large areas with a much larger variety of spatio-temporal dynamics. The event generator produces precipitation events 
which are sequenced along a timeline with dry spells between events. These data can be further processed with hydrological models to produce scenarios of hypothetical floods including previously unobserved extremes and addressing system behaviour of large-scale flood risk systems.

Further, the interplay of different flood drivers may contribute to the generation of extreme floods, as for instance the simultaneous occurrence of extreme precipitation with high soil moisture or snowmelt can result in amplifying effects (e.g. Nied et al., 2013; Schröter et al., 2015; Tarasova et al., 2019). Disregarding such compound events may lead to an incorrect assessment of risk (Zscheischler et al., 2018). In the context of flood risk, the memory of hydro-meteorological systems at different timescales affects the generation of extreme floods. Using a hydrological and hydraulic modelling system Khanal et al. (2019) have investigated the role of soil-moisture and snow for the intensification of extreme floods in the catchment of the Rhine River (Germany). It is shown that meteorological autocorrelation has a strong impact on the magnitude of peak discharge and that the hydrological memory from snow accumulation and soil-moisture complements the generation of extreme discharges. For the case of the Rhine catchment, peak discharges have been reduced by $80 \%$ without meteorological autocorrelation.

These novel approaches allow to producing spatially coherent flood scenarios for large-scale hazard and risk assessments, improved flood risk management plans and simulating compound events to prepare decision-makers for events never experienced to date.

\subsection{New technologies to exploit large data volumes}

Deploying flood models is time-consuming, particularly at large-scale, because various large input datasets have to be processed from different sources. Along with this, the increasing quantity, complexity and resolution of useful datasets imposes a growing demand for skills and knowledge on model developers and users. Furthermore, the frequent update cycles of some datasets may require regular adjustments of deployed models to keep them current. The "LF- 
Ptoolbox" (URL: https://github.com/jsosa/LFPtools) offers a set of programs to automate input data processing for efficient large-scale flood inundation modelling (Sosa et al., 2020). "LFPtoolbox"" programs have been demonstrated in the UK's Severn basin on a model built at $1 \mathrm{~km}$ resolution using publicly available data sets only. Further, these tools made it possible to simulate the river hydraulic and inundation processes in almost 300 European river basins for a period covering the last 26 years at daily time steps and high spatial detail $(90 \mathrm{~m}$ resolution). As such, "LFPtoolbox"" may be used as an intermediate platform to streamline the preparation of local, continental or global flood inundation studies in combination with any hydraulic model.

Still, computational complexity and effort as well as lack of data can constrain the preparation of large-scale flood hazards maps. An alternative approach to increase the availability of flood hazard maps uses terrain analysis of digital elevation models (Tavares da Costa et al., 2019). It builds on a method to downscale coarse flood hazard maps, i.e. enhancing the spatial detail and coverage of flood-prone areas, and to delineate flood-prone areas in river basins where no flood hazard maps are available. This approach yields an envelope flood extent which does not represent hydrodynamic processes, but is instead "shaped" by topography and geomorphological features. Machine learning algorithms are trained to represent non-linear functional relationships of flood maps and geomorphological and hydro-climatic catchment characteristics (Tavares da Costa et al., 2020). The "Smart-Flood" tool (Fig.2) is available as a web application (URL: http://107.23.156.64/webgis/smartflood/?from=) at the global scale. It is fully functional making it a workable and effective solution to stakeholders such as flood managers or insurers.

\subsection{Upstream-downstream interactions as an example for system behaviour}

Accounting for system behaviour such as upstream-downstream interactions is crucial for risk managers to assess flood risk realistically and draft reliable risk management plans. Authorities need this information based on the entire flood risk system, but it also opens new challenges related to data availabil- 


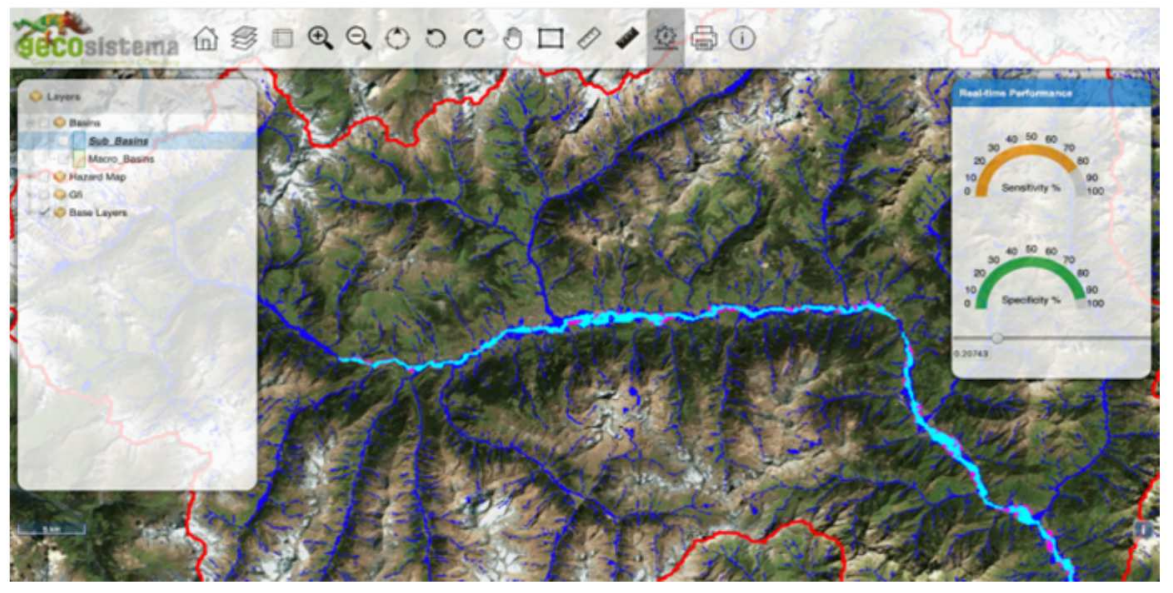

Figure 2: "Smart-Flood" Web-application (Tavares da Costa et al., 2019) showing a sample overlay of the 100-year return period flood hazard map for Europe (Dottori et al., 2016) in cyan color on the downscaled and extrapolated hydrogeomorphic flood-prone areas delineated using the Geomorphic Flood Index (GFI, Samela et al. (2017)) in dark blue color. The GFIbased flood hazard map covers also smaller tributaries, and thus provides a more complete picture of flood prone areas in the region. 
ity and computational costs. In practice, applying such complex modelling frameworks is often not feasible. Recent modelling approaches aim to bridge this gap between complexity and applicability. One of these approaches consists of a simplified levee-breach model for large river systems to represent the upstream-downstream effects of different levee failure processes on water levels and exceedance duration.

Levee failure processes are complex and breaching processes are usually simplified in modelling using fragility curves which give failure probability as a function of water level. While this assumption is reasonable for overtopping, piping processes depend also largely on the duration of high water levels. As a further development of fragility curves, fragility surfaces are introduced as failure probabilities accounting for water level and duration (Curran et al., 2020). This new levee failure modeling concept has been applied in a flood risk study for the Rhine River in the Netherlands. The comparison of system behaviour when accounting for different levee failure scenarios including no levee failure, overtopping, and duration induced failure reveals that duration induced failures mostly occur at a late stage during the flood wave, i.e. after the flood peak. This implies that levees fail when water levels are receding, and thus smaller flood volumes leave the main river and the relief downstream is reduced.

Computational efficient simulations of levee failures in a fully $2 \mathrm{D}$ hydrodynamic model in large areas are needed to more realistically represent flood inundation processes in interaction with topography, flood control and protection schemes in the floodplains including also upstream-downstream interactions. A newly developed extension to the LISFLOOD-FP model (Bates et al., 2010) allows levee-breach analysis locally and in large domains. The new model represents the hydraulic interactions in a river network induced by multiple levee breach locations and the links between channel and floodplain in a fully 2D-mode (Shustikova et al., 2020). This approach is geared towards minimum set-up efforts and data requirements. A benchmark comparison with a more complex 2D model (HEC-RAS 2D, version 5.0.3) has demonstrated its capability to efficiently simulate levee failure and consequent inundation of the pro- 
tected floodplain in $2 \mathrm{D}$ mode. This gives risk modellers enhanced options to represent system behaviour such as backwater effects and backflow processes from the floodplains. Ultimately, risk managers have more realistic scenarios to inform their decisions. Under the solidarity principle of the EU Floods Directive, understanding the effects that levees and levee failures have in terms of shifting risks and being able to swiftly analyse and visualise these effects is useful when planning new risk reduction strategies including structural measures such as levees (Ciullo et al., 2020).

\subsection{Extended analytical frameworks for interactions in human-flood systems}

Flood hazard maps are an important basis for the implementation of the EU Floods Directive 2007/60/EC (EC, 2007). This also requires the provision of flood risk maps and the implementation of flood risk management plans. These plans need to devise risk reduction strategies and specific measures, and need to align with the so-called solidarity principle, one the Directive's key principles. This is particularly relevant for all those systems, both national and transboundary, where upstream-downstream conflicts may arise from the implementation of flood protection measures and consequent spatial redistribution of risk, as discussed above for the example of levee failures. This redistribution of flood risk only becomes visible if larger regions are considered. A new framework for systemic flood risk assessment specifically takes the upstream-downstream conflicts into account in a multi-objective flood risk optimisation approach (Ciullo et al., 2019b). This framework has been applied to the IJssel River (a branch of the Dutch Rhine River) (Ciullo et al., 2019a) and to a trans-boundary stretch of the Rhine River, including Dutch and German protected areas (Ciullo et al., $2019 b, 2020)$.

These applications showed that neglecting system behaviour has two consequences for flood risk management. First, it leads to higher expected annual damages at downstream locations and for the system as a whole (Ciullo et al., 2019a). Second, it leads to a false sense of the equal distribution of flood risk within the system, which can be misleading when deciding upon what area to 
prioritize in the allocation of economic resources to reduce flood risk (Ciullo et al., 2019b).

A system approach to flood risk management accounts for system behaviour and allows revealing the trade-offs between efficiency in risk reduction and equity in risk distribution (Ciullo et al., 2020). Measures which are best at reducing risk for the system as a whole may achieve this at the expense of increased risk in some areas in the system. On the contrary, measures which lead to an almost equal risk distribution may obtain very little overall risk reduction. The new framework allows exploring the Pareto-front of risk management measures with regard to efficiency and equity and identifying the most convenient alternative by balancing both aspects. Flood risk managers may benefit from it, as it permits the quantification of the redistribution of risk and the discovery of interactions and conflicts among riverine communities in the assessment of risk management strategies.

While an improved understanding and more comprehensive estimation of flood risk supports informed decision making, the implementation of flood risk management strategies at the societal level involves numerous sectors with diverse interests and responsibilities divided between many actors. Improving the levels of integration in flood risk management across sectors and between spatial levels can help to take advantage of synergies and/or create additional opportunities. A systematic assessment of the integration context and challenge, associated objectives, relationships between actors responsible to achieve these objectives, influencing mechanisms, and integrated knowledge, policies and interventions form the basis of a new framework for assessing degrees of integration in flood risk management (Cumiskey et al., 2019). Overall, this framework offers an approach to assess the key elements of integration in flood risk management at multiple different geographical and institutional scales to help policy makers and practitioners identify key elements for improvement, such as strengthening specific actor relationships or the availability of governance mechanisms. By taking a systems approach to understanding the governance capacity needed for integration, entry points can be identified for improving multi-actor partic- 
ipation, alignment between flood risk and sector-specific plans, and synergies across interventions in practice. As such, a systems perspective encompasses both the physical system where management interventions are applied and the governance system where decisions are made. These findings point out that adopting a systems perspective has a large potential to reduce flood impacts. These systemic interactions can be harnessed to jointly reduce flood impacts, for example, through improving awareness-raising campaigns that stimulate actions for private precaution by using insights into human behaviour.

Just as floods and society are dynamic, so is flood risk. It changes over time and is responsive to multiple drivers. Risk assessment and management needs to take this into account, so that flood managers can come up with appropriate risk mitigation strategies. However, the flood risk models in use today often only take into account a few flood drivers, which limits their ability to factor in interactions and feedbacks among these drivers, making them prone to biases. The occurrence of floods and severity of impacts has a number of influencing factors, including, for instance, climatic (e.g., increasing rainfall), human (e.g., land-use change), or river channel processes (e.g., levee construction). Including additional drivers into flood risk assessment therefore helps to gain a better understanding of risk. Two questions are of interest in this context: How does each risk driver contribute to changes in flood risk? How do they interact with each other and change flood risk?

Recent research demonstrated that it is possible to attribute flood changes to drivers by analysing past changes. This is the result of a newly developed, data-based framework for the analysis of long-term records of flood data. The exemplary application to Upper Austria linked the increase of floods to more intense rainfall over the past 50 years (Bertola et al., 2019).

On the European scale, trends in the 2-year and 100-year floods were estimated by fitting a regional non-stationary flood frequency model to several regions across Europe where long flood records are pooled following a spatial moving window approach (Bertola et al., 2020). Flood records over five decades were used from 2370 hydrometric stations in Europe. Distinctive patterns of 
flood regime change are detected for large regions across Europe, which depend on flood magnitude and catchment size (Fig.3).

Another approach uses a simulation model of the flood risk chain to examine the sensitivity of flood risk to changes in risk drivers. The example application to the Mulde catchment in Germany shows that changes in levee systems or vulnerability could outweigh changes in climate (Metin et al., 2018). The application of these approaches provides a more complete view to flood risk and helps to prioritise and make decisions more robust for long-term investments in risk reduction.

Temporal changes in vulnerability due to private precautionary measures may significantly alter the impact of flooding, but as knowledge about vulnerability reduction via private precautionary measures is scarce, their effects are hardly considered in loss modeling and risk assessments. However, this is a prerequisite to enable temporally dynamic flood damage and risk modeling, and thus the evaluation of risk management and adaptation strategies. Sairam et al. (2019) have developed a statistically robust methodology to quantify the loss-reducing effect of private precaution from empirical survey data of flood affected households. Further, loss estimation models capable of capturing this loss-reducing effect were identified from state-of-the-art flood loss models. Among the tested models, the rule based multi-factorial model FLEMOps 330 (Thieken et al., 2008) and a Bayesian Network model (Wagenaar et al., 2018; Lüdtke et al., 2019) were capable of capturing the effect of private precaution. Including this effect in loss estimation for risk assessment decreases the common over-estimation of risk for well-prepared communities and vice-versa. This information is useful for insurers, as they can provide customised products and adjust their pricing accordingly.

In addition to such changes in vulnerability, a better understanding of the role of humans in relation to floods is needed. How much damage a flood causes depends largely on the behaviour of the population at risk. Flood-aware communities are often inclined to implement structural protection schemes, but 

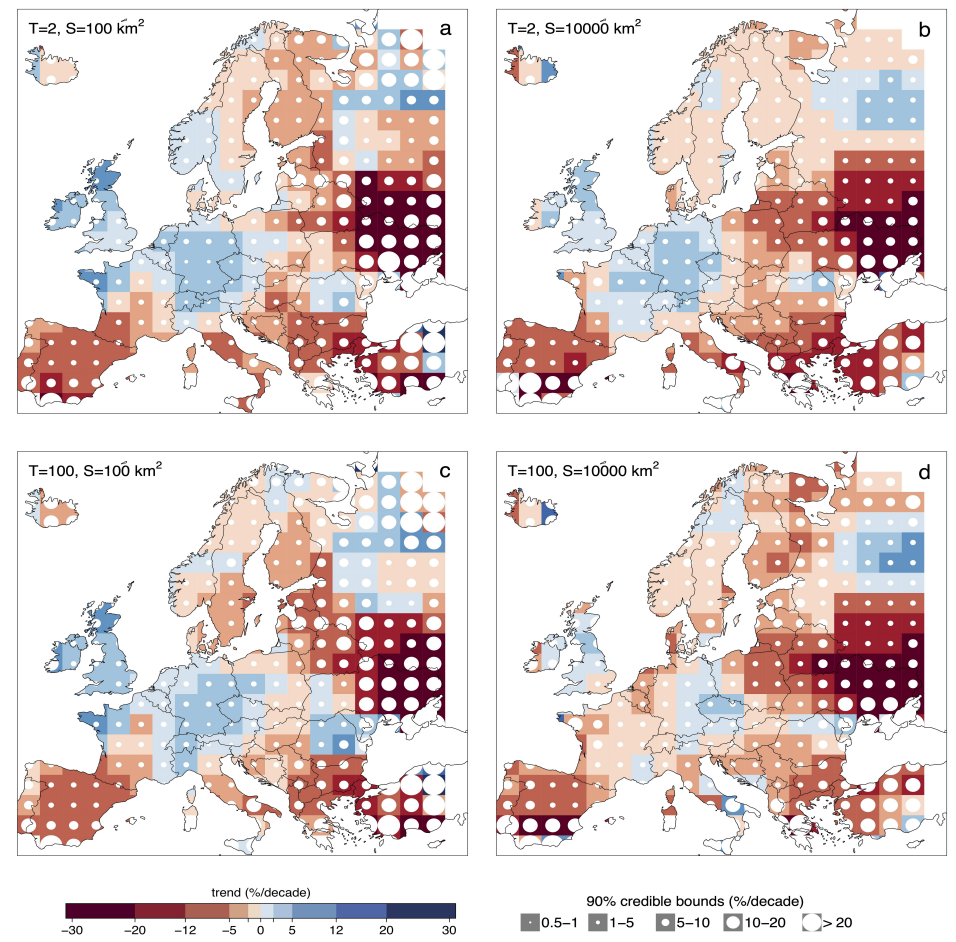

Figure 3: Regional trends in flood discharges across Europe over the period 1960-2010. Panels $\mathrm{a}$ and $\mathrm{b}$ show the trends for the median flood ( $\mathrm{T}=2$ years) and panels $\mathrm{c}$ and $\mathrm{d}$ for the 100-year flood. The flood trends refer to small catchment area $(\mathrm{S}=100 \mathrm{~km} 2)$ in panel a and $\mathrm{c}$ and to large catchment area $(\mathrm{S}=10000 \mathrm{~km} 2)$ in panels b and d. Uncertainty associated with regional flood trends is shown by circles whose size is proportional to the width of the $90 \%$ credibility bounds. From Bertola et al. (2020) 
levels of damage due to the "levee effect" (Tobin, 1995; Baldassarre et al., 2013). Accordingly, if an extreme flood event occurs (exceeding the levee's design level), far more goods are at risk and the damage is much higher. By contrast, a high level of flood risk awareness among the population (e.g. due to frequent flooding), may increase the willingness to take precautionary measures in order to mitigate the impact of floods. Traditionally, flood management decides upon measures based on short term scenarios and cost-benefit analysis, thereby not taking into account the interactions between the physical and human system. This may result in measures being implemented that are most feasible based on these scenarios, but are not the most robust. To understand the long-term effects of measures or changes in the system, it is important to study the humanflood system as a whole. A new socio-hydrological flood model (Barendrecht et al., 2019) provides an improved understanding of such feedbacks through the development of a socio-hydrological flood model. It represents feedbacks within the human-flood system, by quantifying the populations' "forgetfulness". The results of a case study of the Elbe River in Dresden, Germany, show that the experience of flood events positively influences the consciousness of flood risk and leads to an uptake of precautionary measures. Flood risk management may benefit from these results to promote awareness raising campaigns and emphasize the role of private precautionary measures (Barendrecht et al., 2019).

\section{Conclusions}

The highlighted examples of recent advancements in flood risk research demonstrate that an improved understanding of flood risk systems and the availability of more comprehensive information provide a useful basis for wellfounded flood risk assessment and management. Novel tools for implementing the systems approach in flood risk assessment and management are provided which enable the consideration of upstream-downstream interactions within river systems, for instance, due to levee breaches, but also temporal changes in risk, such as the effect of private precaution on flood losses, the processing 
of big data volumes and the simulation of large-scale yet high-resolution flood scenarios and unprecedented compound events. Further, new approaches and methods for adopting a systems perspective in flood risk are provided which allow to comprehensively consider flood risk drivers to gain a better understanding of flood risk, understand and factor in human behaviour, target entry points to improve the integration of actors in risk management practice, as well as the quantification of the redistribution of risk over large scales and the assessment of flood risk management strategies both in terms of risk reduction and equity in risk distribution. Policy-makers and flood risk managers can profit from the Systems approach, as it provides novel methods and tools that offer a more comprehensive view to flood risk, reveal the relevant interactions, and quantify essential feedbacks in flood risk systems. Further, it gives tools for flood hazard and risk assessments that are spatially coherent, consider interactions and cover large spatial scales. This deepened understanding of risk and the enhanced capability to assess risk improves the basis for flood risk assessment and management.

\section{Acknowledgements}

The research conducted within ETN SYSTEM-RISK has received funding from the European Union's Horizon 2020 research and innovation programme under the Marie Skłodowska-Curie grant agreement No 676027

\section{Disclosure}

The authors declare no conflict of interests.

\section{References}

Baldassarre, G.D., Viglione, A., Carr, G., Kuil, L., Salinas, J.L., Blöschl, G., 2013. Socio-hydrology: conceptualising human-flood interactions. Hydrology and Earth System Sciences 17, 3295-3303. URL: https:// 
www.hydrol-earth-syst-sci.net/17/3295/2013/, doi:https://doi.org/ 10.5194/hess-17-3295-2013.

Barendrecht, M.H., Viglione, A., Kreibich, H., Merz, B., Vorogushyn, S., Blöschl, G., 2019. The Value of Empirical Data for Estimating the Parameters of a Sociohydrological Flood Risk Model. Water Resources Research 55, 1312-1336. URL: https://agupubs.onlinelibrary.wiley.com/doi/abs/ 10.1029/2018WR024128, doi:10.1029/2018WR024128.

Bates, P., Horritt, M., Fewtrell, T., 2010. A simple inertial formulation of the shallow water equations for efficient two-dimensional flood inundation modelling. Journal of Hydrology 387, 33-45. URL: http: //linkinghub.elsevier.com/retrieve/pii/S0022169410001538, doi:10. $1016 / j \cdot j$ hydrol .2010 .03 .027$.

Bertola, M., Viglione, A., Blöschl, G., 2019. Informed attribution of flood changes to decadal variation of atmospheric, catchment and river drivers in Upper Austria. Journal of Hydrology 577, 123919. URL: http://www . sciencedirect.com/science/article/pii/S0022169419306390, doi:10. 1016/j.jhydrol . 2019.123919.

Bertola, M., Viglione, A., Lun, D., Hall, J., Blöschl, G., 2020. Flood trends in Europe: are changes in small and big floods different? Hydrology and Earth System Sciences 24, 1805-1822. URL: https:// hess.copernicus.org/articles/24/1805/2020/, doi:https://doi.org/ 10.5194/hess-24-1805-2020. publisher: Copernicus GmbH.

de Bruijn, K., Buurman, J., Mens, M., Dahm, R., Klijn, F., 2017. Resilience in practice: Five principles to enable societies to cope with extreme weather events. Environmental Science \& Policy 70, 21-30. URL: http://www.sciencedirect.com/science/article/pii/ S1462901116305202, doi:10.1016/j.envsci.2017.02.001.

Bubeck, P., Botzen, W.J.W., Kreibich, H., Aerts, J.C.J.H., 2012. Long-term 
development and effectiveness of private flood mitigation measures: an analysis for the German part of the river Rhine. Nat. Hazards Earth Syst. Sci. 12, 3507-3518. doi:10.5194/nhess-12-3507-2012. wOS:000311804900026.

Ciullo, A., Bruijn, K.M.d., Kwakkel, J.H., Klijn, F., 2019a. Accounting for the uncertain effects of hydraulic interactions in optimising embankments heights: Proof of principle for the IJssel River. Journal of Flood Risk Management 12, e12532. URL: https://onlinelibrary.wiley. com/doi/abs/10.1111/jfr3.12532, doi:10.1111/jfr3.12532. _eprint: https://onlinelibrary.wiley.com/doi/pdf/10.1111/jfr3.12532.

Ciullo, A., De Bruijn, K.M., Kwakkel, J.H., Klijn, F., 2019b. Systemic Flood Risk Management: The Challenge of Accounting for Hydraulic Interactions. Water 11, 2530. URL: https://www.mdpi.com/2073-4441/11/12/2530, doi:10.3390/w11122530.

Ciullo, A., Kwakkel, J.H., De Bruijn, K.M., Doorn, N., Klijn, F., 2020. Efficient or Fair? Operationalizing Ethical Principles in Flood Risk Management: A Case Study on the Dutch-German Rhine. Risk Analysis , risa.13527URL: https://onlinelibrary.wiley.com/doi/abs/10.1111/ risa.13527, doi:10.1111/risa.13527.

Tavares da Costa, R., Manfreda, S., Luzzi, V., Samela, C., Mazzoli, P., Castellarin, A., Bagli, S., 2019. A web application for hydrogeomor445 phic flood hazard mapping. Environmental Modelling \& Software 118, 172-186. URL: http://www.sciencedirect.com/science/article/pii/ S1364815218307953, doi:10.1016/j.envsoft.2019.04.010.

Tavares da Costa, R., Zanardo, S., Bagli, S., Hilberts, A.G.J., Manfreda, S., Samela, C., Castellarin, A., 2020. Predictive Modeling of Envelope Flood Extents Using Geomorphic and ClimaticHydrologic Catchment Characteristics. Water Resources Research 56, e2019WR026453. URL: https://onlinelibrary.wiley.com/ 
doi/abs/10.1029/2019WR026453, doi:10.1029/2019WR026453. _eprint: https://agupubs.onlinelibrary.wiley.com/doi/pdf/10.1029/2019WR026453.

CRED, 2015. The human cost of natural disasters: a global perspective. Technical Report. Centre for Research on the Epidemiology of Disasters. URL: https://www. preventionweb.net/publications/view/42895.

Cumiskey, L., Priest, S., Klijn, F., Juntti, M., 2019. A framework to assess integration in flood risk management: implications for governance, policy, and practice. Ecology and Society 24. URL: https://www . ecologyandsociety . org/vol24/iss4/art17/, doi:10.5751/ES-11298-240417.

Curran, A., Bruijn, K.M.D., Kok, M., 2020. Influence of water level duration on dike breach triggering, focusing on system behaviour hazard analyses in lowland rivers. Georisk: Assessment and Management of Risk for Engineered Systems and Geohazards 14, 26-40. URL: https://doi.org/10.1080/ 17499518.2018.1542498, doi:10.1080/17499518.2018.1542498. publisher: Taylor \& Francis _eprint: https://doi.org/10.1080/17499518.2018.1542498.

Diederen, D., Liu, Y., 2019. Dynamic spatio-temporal generation of largescale synthetic gridded precipitation: with improved spatial coherence of extremes. Stoch Environ Res Risk Assess URL: https://doi.org/10.1007/ s00477-019-01724-9, doi:10.1007/s00477-019-01724-9.

Diederen, D., Liu, Y., Gouldby, B., Diermanse, F., Vorogushyn, S., 2019. Stochastic generation of spatially coherent river discharge peaks for continental event-based flood risk assessment. Natural Hazards and Earth System Sciences 19, 1041-1053. URL: https: //www.nat-hazards-earth-syst-sci.net/19/1041/2019/, doi:https:// doi.org/10.5194/nhess-19-1041-2019.

Dottori, F., Alfieri, L., Salamon, P., Bianchi, A., Feyen, L., Lorini, V., 2016. Flood hazard map for Europe - 100-year return period URL: http://data.europa.eu/89h/jrc-floods-floodmapeu_rp100y-tif. publisher: European Commission, Joint Research Centre (JRC). 
EC, 2007. Directive 2007/60/EC of the European Parliament and of the Council on the assessment and management of flood risks.

Falter, D., Schröter, K., Dung, N., Vorogushyn, S., Kreibich, H., Hundecha, Y., Apel, H., Merz, B., 2015. Spatially coherent flood risk assessment based on long-term continuous simulation with a coupled model chain. Journal of Hydrology 524, 182-193. URL: http://www.sciencedirect.com/science/ article/pii/S002216941500133X, doi:10.1016/j.jhydrol.2015.02.021.

Khanal, S., Lutz, A.F., Immerzeel, W.W., Vries, H.d., Wanders, N., Hurk, B.v.d., 2019. The Impact of Meteorological and Hydrological Memory on Compound Peak Flows in the Rhine River Basin. Atmosphere 10, 171. URL: https://www.mdpi.com/2073-4433/10/4/171, doi:10.3390/ atmos 10040171.

Klijn, F., Kreibich, H., de Moel, H., Penning-Rowsell, E., 2015. Adaptive flood risk management planning based on a comprehensive flood risk conceptualisation. Mitig Adapt Strateg Glob Change 20, 845-864. URL: https://doi. org/10.1007/s11027-015-9638-z, doi:10.1007/s11027-015-9638-z.

Lüdtke, S., Schröter, K., Steinhausen, M., Weise, L., Figueiredo, R., Kreibich, H., 2019. A Consistent Approach for Probabilistic Residential Flood Loss Modeling in Europe. Water Resources Research 55, 1061610635. URL: https://agupubs.onlinelibrary.wiley.com/doi/abs/10. 1029/2019WR026213, doi:10.1029/2019WR026213.

Merz, B., Friedrich, J., Disse, M., Schwarz, J., Goldammer, J., Wächter, J., 2006. Possibilities and Limitations of Interdisciplinary, User-oriented Research: Experiences from the German Research Network Natural Disasters. Nat Hazards 38, 3-20. URL: https://doi.org/10.1007/ s11069-005-8597-1, doi:10.1007/s11069-005-8597-1.

Merz, B., Vorogushyn, S., Lall, U., Viglione, A., Blöschl, G., 2015. Charting unknown waters - On the role of surprise in flood risk assessment and manage- 
ment. Water Resour. Res., n/a-n/aURL: http://onlinelibrary.wiley. com/doi/10.1002/2015WR017464/abstract, doi:10.1002/2015WR017464.

Metin, A., Dung, N., Schröter, K., Guse, B., Apel, H., Kreibich, H., Vorogushyn, S., Merz, B., 2018. How do changes along the risk chain affect flood risk? Natural Hazards and Earth System Sciences 18, 30893108. URL: https://www.nat-hazards-earth-syst-sci.net/18/3089/ 2018/, doi:https://doi.org/10.5194/nhess-18-3089-2018.

Metin, A.D., Dung, N.V., Schröter, K., Vorogushyn, S., Guse, B., Kreibich, H., Merz, B., 2020. The role of spatial dependence for large-scale flood risk estimation. Natural Hazards and Earth System Sciences 20, 967-979. URL: https://www.nat-hazards-earth-syst-sci.net/20/ 967/2020/, doi:https://doi .org/10.5194/nhess-20-967-2020. publisher: Copernicus GmbH.

Nied, M., Hundecha, Y., Merz, B., 2013. Flood-initiating catchment conditions: a spatio-temporal analysis of large-scale soil moisture patterns in the Elbe River basin. Hydrol. Earth Syst. Sci. 17, 1401-1414. URL: http://www.hydrol-earth-syst-sci.net/17/1401/2013/, doi:10 . 5194/hess-17-1401-2013.

Pinter, N., 2005. One Step Forward, Two Steps Back on U.S. Floodplains. Science 308, 207-208. URL: http://science.sciencemag.org/content/ 308/5719/207, doi:10.1126/science.1108411.

Remo, J.W.F., Carlson, M., Pinter, N., 2012. Hydraulic and flood-loss modeling of levee, floodplain, and river management strategies, Middle Mississippi River, USA. Nat Hazards 61, 551-575. URL: http://link.springer.com/ 10.1007/s11069-011-9938-x, doi:10.1007/s11069-011-9938-x.

${ }_{535}$ Sairam, N., Schröter, K., Lüdtke, S., Merz, B., Kreibich, H., 2019. Quantifying Flood Vulnerability Reduction via Private Precaution. Earth's Future 7, 235-249. URL: https://agupubs.onlinelibrary.wiley.com/doi/abs/ 10.1029/2018EF000994, doi:10.1029/2018EF000994. 
Samela, C., Troy, T., Manfreda, S., 2017. Geomorphic classifiers for flood-prone areas delineation for data-scarce environments. Advances in Water Resources 102, 13-28. doi:10.1016/j .advwatres.2017.01.007.

Schröter, K., Kunz, M., Elmer, F., Mühr, B., Merz, B., 2015. What made the June 2013 flood in Germany an exceptional event? A hydro-meteorological evaluation. Hydrol. Earth Syst. Sci. 19, 309-327.

Shustikova, I., Neal, J.C., Domeneghetti, A., Bates, P.D., Vorogushyn, S., Castellarin, A., 2020. Levee Breaching: A New Extension to the LISFLOODFP Model. Water 12, 942. URL: https://www.mdpi.com/2073-4441/12/4/ 942, doi:10.3390/w12040942. number: 4 Publisher: Multidisciplinary Digital Publishing Institute.

Sosa, J., Sampson, C., Smith, A., Neal, J., Bates, P., 2020. A toolbox to quickly prepare flood inundation models for LISFLOOD-FP simulations. Environmental Modelling \& Software 123, 104561. URL: http://www. sciencedirect.com/science/article/pii/S1364815219307637, doi:10. 1016/j.envsoft. 2019.104561.

Tarasova, L., Merz, R., Kiss, A., Basso, S., Blöschl, G., Merz, B., Viglione, A., Plötner, S., Guse, B., Schumann, A., Fischer, S., Ahrens, B., Anwar, F., Bárdossy, A., Bühler, P., Haberlandt, U., Kreibich, H., Krug, A., Lun, D., Müller-Thomy, H., Pidoto, R., Primo, C., Seidel, J., Vorogushyn, S., Wietzke, L., 2019. Causative classification of river flood events. WIREs Water , e1353URL: https://onlinelibrary.wiley.com/doi/abs/10.1002/wat2. 1353, doi:10.1002/wat2.1353.

Thieken, A., Olschewski, A., Kreibich, H., Kobsch, S., Merz, B., 2008. Development And Evaluation Of Flemops - A New Flood Loss Estimation Model For The Private Sector. Development and Evaluation of FLEMOps-A New Flood Loss Estimation MOdel for the Private Sector URL: www. scopus.com. 
Thieken, A.H., Kienzler, S., Kreibich, H., Kuhlicke, C., Kunz, M., Mühr, B., Müller, M., Otto, A., Petrow, T., Pisi, S., Schröter, K., 2016. Review of the flood risk management system in Germany after the major flood in 2013. Ecology and Society 21. URL: http://www . ecologyandsociety.org/vol21/ iss2/art51/, doi:10.5751/ES-08547-210251.

Tobin, G., 1995. The Levee Love Affair: A Stormy Relationship?1. JAWRA Journal of the American Water Resources Association 31, 359-367. URL: https://onlinelibrary.wiley.com/doi/abs/10.1111/j . 1752-1688.1995.tb04025.x, doi:10.1111/j.1752-1688.1995.tb04025.x.

Vorogushyn, S., Bates, P., Bruijn, K., Castellarin, A., Kreibich, H., Priest, S., Schröter, K., Bagli, S., Blöschl, G., Domeneghetti, A., Gouldby, B., Klijn, F., Lammersen, R., Neal, J., Ridder, N., Terink, W., Viavattene, C., Viglione, A., Zanardo, S., Merz, B., 2018. Evolutionary leap in largescale flood risk assessment needed. Wiley Interdisciplinary Reviews: Water 5, e1266. URL: https://onlinelibrary.wiley.com/doi/abs/10.1002/wat2. 1266, doi:10.1002/wat2.1266.

Vorogushyn, S., Lindenschmidt, K.E., Kreibich, H., Apel, H., Merz, B., 2012. Analysis of a detention basin impact on dike failure probabilities and flood risk for a channel-dike-floodplain system along the river Elbe, Germany. Journal of Hydrology 436-437, 120-131. URL: http://www.sciencedirect. com/science/article/pii/S0022169412001928, doi:10.1016/j.jhydrol. 2012.03 .006 .

Wagenaar, D., Lüdtke, S., Schröter, K., Bouwer, L., Kreibich, H., 2018. Regional and Temporal Transferability of Multivariable Flood Damage Models. Water Resources Research 54, 3688-3703. URL: http://doi.wiley.com/10.1029/ 2017WR022233, doi:10.1029/2017WR022233.

Ward, P.J., Jongman, B., Aerts, J., Bates, P., Botzen, W., Loaiza, A., Hal- 
global framework for future costs and benefits of river-flood protection in urban areas. Nature Climate Change 7, 642. URL: https://www.nature.com/ articles/nclimate3350, doi:10.1038/nclimate3350.

Wyżga, B., Kundzewicz, Z.W., Konieczny, R., Piniewski, M., Zawiejska, J., Radecki-Pawlik, A., 2018. Comprehensive approach to the reduction of river flood risk: Case study of the Upper Vistula Basin. Science of The Total Environment 631-632, 1251-1267. URL: http://www. sciencedirect.com/science/article/pii/S0048969718307708, doi:10. 1016/j.scitotenv. 2018.03.015.

Zscheischler, J., Westra, S., van den Hurk, B.J.J.M., Seneviratne, S.I., Ward, P.J., Pitman, A., AghaKouchak, A., Bresch, D.N., Leonard, M., Wahl, T., Zhang, X., 2018. Future climate risk from compound events. Nature Climate Change 8, 469-477. URL: https://www.nature.com/articles/ s41558-018-0156-3, doi:10.1038/s41558-018-0156-3. number: 6 Publisher: Nature Publishing Group. 